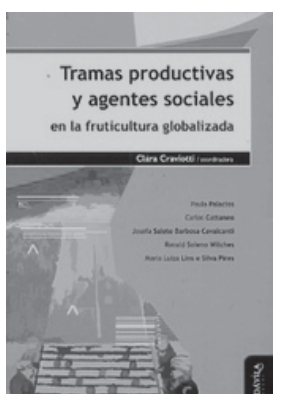

\title{
Craviotti, C. (coordinadora). Tramas productivas y agentes sociales en la fruticultura globalizada
}

\author{
Buenos Aires: Miño y Dávila Editores, 2012. 256 p.
}

\author{
Ana Laura García ${ }^{1}$
}

En las últimas décadas los sistemas agroalimentarios de América Latina han atravesado por profundas transformaciones, entre las que se encuentran la conformación de circuitos globalizados de producción y consumo. El desarrollo de estos circuitos induce cambios en la dinámica de los territorios involucrados y plantea interrogantes sobre las posibilidades que los mismos revisten para alcanzar un desarrollo sustentable y equitativo.

En líneas generales, estas transformaciones se caracterizan por nuevas formas de coordinación entre agentes, mayores requisitos de capital, escala y calidad para el acceso a los mercados, la transnacionalización de ciertos eslabones y la posición dominante de los agentes ubicados en la etapa de distribución de las tramas productivas. No obstante, la presencia de pequeños y medianos productores en estas tramas invita a reflexionar sobre sus condiciones de permanencia y sobre la forma en que la reestructuración productiva es socialmente regulada en los niveles locales.

En el marco de estos interrogantes, en Tramas productivas y agentes sociales en la fruticultura globalizada, investigadores provenientes de disciplinas complementarias exploran los agentes, los vínculos verticales y horizontales que los ligan y las dinámicas territoriales resultantes en un conjunto de

\footnotetext{
1 Universidad de Concepción del Uruguay (Uruguay). E-mail: agarcia@concepcion.inta.gov.ar
}

producciones de contraestación para mercados del Hemisferio Norte: cítricos dulces y arándano en la subregión del río Uruguay del nordeste argentino, mango y uva en el Valle de San Francisco del nordeste brasileño.

Un primer eje de preocupaciones gira en torno a establecer a través de qué mecanismos se produce la inserción de los pequeños y medianos productores en estas tramas, profundizando en los vínculos verticales que los conectan con agentes de otras etapas de la cadena y en experiencias de articulación horizontal como vía alternativa de participación en los mercados. Un segundo eje se relaciona con las implicancias territoriales de los comportamientos desplegados por los agentes de las mismas y los cambios en la inserción internacional de estos cultivos.

Esta tarea se encara desde una mirada que recupera elementos de los enfoques de cadenas globales de valor y de clusters o distritos industriales en lo que atañe al análisis de cadenas y las modalidades de coordinación, la existencia de relaciones de cooperación que dan lugar a sinergias y aumentan la competitividad local, pero los complejiza introduciendo el análisis de las asimetrías y los conflictos. Así, un primer supuesto consiste en que las tramas productivas no están exentas de tensiones y que las mismas obedecen a las diferentes posiciones ocupadas por los agentes, su grado de acceso a recursos y sus variadas lógicas de reproducción y acumulación. Complementariamente, los autores sostienen que el territorio debe ser abordado 
como una construcción social en la que participa un conjunto heterogéneo de agentes con distintas relaciones con el espacio local y como expresión de la tensión entre lo local y lo global.

El libro se centra especialmente en el período que se inicia con la devaluación argentina del año 2002 y el escenario que la misma abre, pero se apoya en una perspectiva multiescalar y procesual que permite articular el espacio local con otros y reconstruir la evolución histórica de las producciones analizadas. La metodología combina el análisis de fuentes secundarias (censos, estadísticas sectoriales, documentos técnicos) con información primaria generada a través de entrevistas a distintos actores de las tramas productivas analizadas.

En el capítulo 1 se analizan las reconfiguraciones experimentadas por los pequeños y medianos productores citrícolas generadas por la reestructuración de la citricultura del noreste argentino en las últimas décadas. Tradicionalmente realizada por pequeños y medianos productores con largas trayectorias vinculadas al citrus y orientada al mercado interno, la devaluación del año 2002 impulsó la reorientación de la actividad hacia la exportación, generando transformaciones a nivel territorial y redefiniendo el lugar de los agentes de esta trama productiva. Las empresas empacadoras integradas verticalmente lograron insertarse en diferentes mercados (internos y externos) y consolidar su posición central, pero los pequeños y medianos productores registraron procesos no lineales. Si bien su número no ha decrecido, algunos exhiben trayectorias de retroceso mientras otros no solo persisten en la actividad sino logran capitalizarse. Estos productores conforman un sector profundamente heterogéneo por sus formas de organizar la producción, nivel tecnológico, dinámica del hogar y localización espacial, factores que dan lugar a variadas estrategias de comercialización e inserción en los mercados interno y externo que condicionan sus posibilidades de persistencia en el mediano plazo. En base a los elementos presentados, los autores plantean la hipótesis de una estructura agraria en redefinición en la cual se estaría consolidando el segmento familiar-empresarial y empresarial en base a la integración vertical de algunas actividades para acceder de manera más directa al mercado interno y la exportación parcial de la producción.

El capítulo 2 explora las modalidades de coordinación entre las diversas etapas que componen la cadena citrícola orientada a la exportación de la subregión oriental del río Uruguay. Las firmas empacadoras-exportadoras conforman un sector dinámico pero reducido y con rasgos disímiles, coexistiendo firmas integradas verticalmente con otras que solo participan en la fase de empaque/comercialización y consorcios o cooperativas de productores que comercializan la producción de sus asociados. Estas firmas despliegan distintas formas de articulación con los pequeños y medianos productores (vía mercado y cuasi integración), los que en general se ubican en la fase productiva y comercializan su producción de manera atomizada, participando de manera subordinada en los vínculos con las empresas empacadoras. Sin embargo, la fase de comercialización a nivel internacional se encuentra controlada por distribuidores y grandes cadenas de supermercados. Los autores plantean que si bien es posible postular la permanencia de esta pluralidad en las formas de coordinación, el fortalecimiento de iniciativas de articulación horizontal (aunque con productores medianos), señala la factibilidad del camino asociativo. De todas formas, plantea interrogantes sobre las consecuencias de una mayor inserción global para los pequeños productores.

El capítulo identifica, por último, una serie de acuerdos entre las firmas que permiten visualizar las sinergias existentes a nivel local y que representan pasos hacia una mayor regulación de la actividad citrícola a escala territorial.

Los capítulos 3 y 4 analizan dos experiencias asociativas (una sociedad anónima y una cooperativa) como mecanismos de acceso de los pequeños y medianos citricultores al mercado global. Si bien exhiben distintas formas de gestión y operatoria comercial, las trayectorias de estos emprendimientos presentan algunos puntos en común: surgen en el contexto de crisis de finales de la década del 1990 e inicios de la siguiente, con el objetivo de construir un canal de comercialización propio. Luego de una primera etapa 
marcada por la inestabilidad y las dificultades para comercializar y afrontar deudas, logran insertarse en el mercado externo. La inserción exportadora permitió obtener mejores precios y nuevos mercados, acceder a nuevas tecnologías y formas de gestión y ampliar la superficie, pero también implicó mayores demandas de capital a nivel predial y del emprendimiento. Esto indujo un proceso de diferenciación interna que llevó a la salida de los productores más pequeños o que situó en una posición frágil a los que permanecieron y promovió el fortalecimiento de los productores medianos o grandes y el desarrollo de una lógica más empresarial entre sus socios. Los casos estudiados señalan las posibilidades del camino asociativo para la permanencia de los pequeños y medianos productores y para un desarrollo territorial más equitativo, pero advierten sobre la necesidad de desarrollar mecanismos que faciliten una mejor inserción de los productores más pequeños en este tipo de emprendimientos.

El capítulo 5 aborda la problemática de las transformaciones espaciales y sociales que genera la inserción de territorios locales en cadenas globales de valor. Se presentan los rasgos del cultivo del arándano en la región del río Uruguay y las tensiones vinculadas a los cambios en su inserción internacional, prestando especial atención a las reconfiguraciones territoriales y de los agentes. El cultivo surge en los años 90, impulsado por viveristas y empresas comercializadoras que reconocen en la región buenas condiciones agroecológicas, la existencia de saberes locales y una red comercial, de servicios e infraestructura relacionados con la producción de cítricos aprovechables y la complementación de los ciclos productivos de ambos cultivos. En su etapa de expansión, crece a partir de la acción de emprendedores extraagrarios que realizaron grandes inversiones $y$, en menor medida, pequeños empresarios citrícolas. Luego de la devaluación del peso en el año 2002 esta producción adquiere mayor dinamismo aún, exportándose a Estados Unidos y Europa como producción de contraestación, con una ventana de exportación restringida.

Desde el año 2007 el cultivo atraviesa una etapa de redefinición caracterizada por la entrada en producción de nuevas zonas, el aumento del volumen de fruta ofertada y una baja del precio internacional del arándano. Estos factores generan incertidumbre y redefinen las características del mercado, las posibilidades de inserción de algunos agentes y desestabiliza las economías locales. La crisis internacional del 2008 profundiza las dificultades y lleva al endeudamiento de productores, la instrumentación de subsidios por parte del estado provincial y nacional y el despliegue de distintas estrategias para permanecer, como la reducción de superficie y costos, recurrir a ayudas familiares, asociarse y avanzar en el empaque. Los distribuidores y las compañías exportadoras que operan en otros países y, en muchos casos, son controladas directamente por distribuidores norteamericanos, emergen como los mejor ubicados en la cadena.

Así, este caso ilustra la problemática de las producciones orientadas exclusivamente a mercados globales y los desafíos que plantean a los actores locales y al estado en materia de regulación de la competencia interregional.

En el capítulo 6 se analizan las estrategias y la inserción en el espacio local de las firmas comercializadoras de arándano que operan en el noreste argentino. El análisis de las estrategias de estas empresas permite comprender el interjuego entre diferentes escalas y captar la forma en que inciden sobre los productores y los territorios en los cuales operan. Las estrategias de las empresas de origen extralocal se caracterizan por exhibir formas flexibles y descentralizadas de gestión y diversificación de zonas de aprovisionamiento que acarrean un bajo compromiso con el territorio. De todas formas, la posesión de tierras e instalaciones a través de los socios que las integran o de productores fidelizados sugiere matizar la imagen de desterritorialización. Las empresas locales, por el contrario, poseen activos fijos y visualizan al arándano como una actividad complementaria del citrus que permite extender el ciclo anual de operaciones y licuar costos fijos. De esta manera, se realizan inversiones para adaptar las instalaciones, se capacita al personal y se aprovechan los canales comerciales ya establecidos.

Ante los cambios del mercado mundial de arándanos, las empresas ensayan diver- 
sas estrategias productivas, de desarrollo de acuerdos y alianzas, de comercialización, prestación de servicios, etc., que evidencian una profundización de la estrategia de flexibilización y da lugar a la conformación de redes cada vez más complejas y extensas. Como contrapunto, se percibe una búsqueda de acuerdos estables con proveedores de servicios clave y con productores seleccionados. Por todo lo anterior, los autores sostienen que no se visualiza una estrategia de territorialización de la producción arandanera, configurando un escenario en el que las sinergias son aún limitadas y la posición de los pequeños y medianos productores es crecientemente vulnerable.

El capítulo 7 analiza la conformación de agrupamientos colectivos de productores para la exportación directa del arándano interesándose en los mismos como ámbitos de cooperación entre agentes productivos y como ejemplos para evaluar la incidencia del territorio en tanto red de relaciones que incluye a las organizaciones locales y diferentes tipos de relaciones informales.

Los agrupamientos de comercialización de productores en pequeña escala surgen como una estrategia defensiva frente a la tendencia a la disminución de los precios recibidos de las compañías comercializadoras y el riesgo de ser excluidos como proveedores. La consolidación y el aumento del volumen exportado dan cuenta de los logros susceptibles de ser alcanzados por este tipo de emprendimientos. Asimismo, factores como la confianza, un liderazgo compartido y diferenciado según las respectivas áreas de competencia, la homogeneidad del perfil y el tamaño reducido de los emprendimientos favorecen el conocimiento mutuo y la identificación de un proyecto organizativo común. No obstante, la trayectoria de estos agrupamientos incluye el desgranamiento de los miembros iniciales, debido a requerimientos materiales y simbólicos. Adicionalmente, la ausencia de una visión socialmente incluyente obstaculiza una incidencia mayor del emprendimiento a nivel del espacio local. El capítulo concluye, por lo tanto, que agrupamientos de comercialización asociativos como el estudiado permitirían compensar (al menos en parte) la posición relativamente desventajosa de los pequeños y medianos productores respecto a otros agentes de la cadena agroalimentaria pero requerirían de una orientación integradora por parte de sus miembros y del entramado institucional local, a fin de lograr un mayor anclaje a nivel territorial de las producciones orientadas a mercados globales.

El último capítulo analiza el impacto de la crisis internacional de 2008-2009 sobre los distintos actores del Valle de San Francisco (Brasil), las estrategias desplegadas por los mismos y las lecciones aprendidas.

El Valle de San Francisco es una región del nordeste de Brasil caracterizada por condiciones agroecológicas, productivas, tecnológicas y económicas (locales y globales) ventajosas, que la transformaron en una de las áreas más dinámicas de producción de uvas y mango, conformando un territorio local fuertemente inserto en el mercado global de frutas frescas. Sin embargo, ante la crisis mundial de 2008-2009 los productores sufrieron la retracción de la demanda y la baja de los precios, lo que llevó al endeudamiento, la reducción del área cultivada y del empleo, con el consiguiente aumento de la conflictividad territorial.

En este escenario, algunos productores recurrieron a la conformación de cooperativas de comercialización. La mayoría de estas cooperativas exhiben rasgos de un nuevo modelo de cooperativas: flexibilidad, externalización de costos fijos, profesionalismo. Sus integrantes son de tamaño medio o grande, poseen superficies irrigadas, otras fuentes de ingresos y un alto profesionalismo. Se unieron para conformar cámaras de frío, identificadas como necesidad para garantizar las exportaciones y para disminuir los costos relativos a la exportación y de difícil acceso en forma individual.

La participación de los productores en emprendimientos colectivos aumenta el poder de decisión de los mismos, permitiéndoles el acceso a una mayor variedad de estrategias empresariales de gran alcance. Así las cooperativas aparecen como una forma competitiva de inserción en el mercado en tiempos de crisis y como una posibilidad de minimizar riesgos, lo cual lleva a reconocer su papel en los procesos de reconfiguración de espacios rurales. Otras estrategias fueron 
la diversificación de productos y mercados, en los que entró a jugar un papel más importante el mercado doméstico, el desarrollo de la industria procesadora y la producción orgánica. Así, se despliegan nuevas dinámicas territoriales ante la crisis global. La crisis internacional reveló la vulnerabilidad de una región fuertemente orientada a la producción de frutas exóticas de contraestación para el mercado externo. La importancia del trabajo se encuentra en poner en cuestión/debate la vulnerabilidad de las Ilamadas regiones globlaes y dinámicas de la agricultura de exportación en el medio de la crisis estructurales e identificar las diversas estrategias utilizadas por los productores en sus actividades productivas, revelando la redefinición de las estrategias organizacionales y el margen de acción de los diversos actores. El cooperativismo como alternativa colectiva para superar dificultades.

En síntesis, los trabajos reunidos en este libro permiten ver que las reconfiguraciones que las producciones estudiadas han experimentado en los últimos diez-quince años han sido de variada intensidad. En el caso del arándano, los acelerados cambios del mercado global terminan imponiéndose sobre los espacios locales involucrados. Lo mismo sucede en Brasil con las producciones de mango y uvas. La producción citrícola, en cambio, si bien presenta dificultades en fun- ción de la contracción del mercado interno, posee una mayor fortaleza relativa en tanto presenta mercados y destinos diversificados, un período de comercialización más amplio y forma parte de estructuras diversificadas de producción. Así, uno de sus principales hallazgos es que las políticas orientadas a generar polos productivos de exportación basadas en actividades agrarias deberían contemplar el desarrollo de distintos mercados y alternativas de procesamiento de la producción a fin de evitar la vulnerabilidad de las regiones y los actores vinculados a las mismas si se achican las ventanas o se reduce la rentabilidad, lo que afecta particularmente a trabajadores $y$ pequeños y medianos productores.

En relación con las formas de inserción de los pequeños y medianos productores en cadenas direccionadas por la demanda, el análisis desplegado establece su mayor vulnerabilidad en términos relativos, pero también su capacidad para desarrollar diferentes estrategias tendientes a renegociar sus condiciones de inserción. En esta dirección, los agrupamientos a través de consorcios o cooperativas, si bien muchas veces no logran sustentarse en el tiempo por carencia de apoyo en sus fases iniciales, son herramientas que posibilitan la adquisición de bienes e instalaciones (plantas de empaque, cámaras de frío), el logro de aprendizajes, mejora de la capacidad de negociación. 
